\title{
Los nuevos discursos del management: difusión, impactos y resistencias
}

\author{
New Management Discourses: Difussion, impacts \\ and resistances
}

CARLOS JESÚS FERNÁNDEZ RODRÍGUEZ y MARIA MEDINA-VICENT**

UnIVERSIDAd AutónOMa de MADrid / Universitat Jaume I

CARLOS.FERNANDEZ@UAM.ES / MEDINAM@UJI.ES

El presente monográfico de Recerca titulado «Los nuevos discursos del management: contribuciones desde una perspectiva crítica», se compone de siete artículos de investigación y dos recensiones. A través de los diferentes escritos se pretende realizar un recorrido por el estado actual de los discursos del management y sus repercusiones no solo en el mundo del trabajo, sino en el grueso de la sociedad desde una perspectiva crítica.Así pues, a lo largo de las siguientes páginas el/la lector/a podrá transitar por los diferentes discursos que hoy en día caracterizan el espacio social. Nos referimos a marcos generales de sentido como el individualismo y la descolectivización de lo social, pero también a cuestiones más concretas como el emprendimiento y la precariedad; todos ellos componentes que conforman el escenario al que nos estamos remitiendo en todo momento, esto es, el del discurso neoliberal o el «nuevo espíritu del capitalismo» (Boltanski y Chiapello, 2002).

El discurso gerencial o del management representa, de alguna manera, la ideología de aquellos que detentan el poder dentro de las organizaciones empresariales (llamémosles empresarios/as, gerentes, ejecutivos/as, emprendedores/as, directivos/as o cuadros intermedios), pese a que, $a$ priori, sus objetivos explícitos no irían más allá de proporcionar un conjunto de recetas e ideas fuertes para desarrollar una gestión eficaz y eficiente de las organizaciones, tanto empresariales como, cada vez más, de

\footnotetext{
Maria Medina-Vicent forma parte del Proyecto de Investigación Científica y Desarrollo Tecnológico «Neuroeducación moral para las éticas aplicadas» [FFI2016-76753-c2-2-P], financiado por el Ministerio Español de Economía y Competitividad; así como del proyecto de investigación «El potencial de las éticas aplicadas en las herramientas de participación del Gobierno Abierto y la Sociedad Civil» [ujIA2016-04], financiado por la Universitat Jaume I»
} 
otros ámbitos (Fernández Rodríguez, 2007b). Sin embargo, a un nivel implícito, este discurso ejerce un papel clave en la definición y legitimación social de los significados e imágenes sobre la empresa, permitiendo que las lógicas económicas asociadas a la actividad empresarial y el mercado se difundan en todos los ámbitos sociales.

Proporciona, de manera muy sugerente, una descripción vívida, aunque a la vez sutil, de la subjetividad en la sociedad neoliberal contemporánea (Laval y Dardot, 2013). De hecho, sus postulados se aceptan en la actualidad como si estos fueran simple «sentido común», algo natural y de necesaria aplicación, a la vez que son además impulsadas por expertos (consultores/as, empresarios/as de éxito) que en algunos casos alcanzan la categoría de gurús de la gestión (Gantman, 2005; Fernández Rodríguez, 2007b; Alonso y Fernández Rodríguez, 2013). Teniendo en cuenta que la lógica empresarial se encuentra profundamente entrelazada con los discursos políticos y sociales actuales, identificar los rasgos centrales del denominado imaginario managerial (Alonso y Fernández Rodríguez, 2006) nos permitirá abordar de forma novedosa el análisis del escenario actual, caracterizado por una importante efervescencia en el terreno político (Powell, 2015; Tormey, 2015) y, al mismo tiempo, grandes convulsiones en el terreno económico, en el que la denominada «nueva razón del mundo» neoliberal (Laval y Dardot, 2013) está modelando de forma decisiva las organizaciones, economías y sociedades actuales. Asimismo, nos permitirá reflexionar sobre la proliferación de ideas productivistas asociadas a la gestión de uno/a mismo/a -llámese excelencia, emprendimiento, flexibilidad, innovación- que están teniendo unos efectos extraordinarios no ya sobre el paisaje laboral, sino particularmente sobre las subjetividades contemporáneas, poniendo el tiempo vital, las tareas y las ideas creativas al servicio de la rentabilización de las actividades productivas y de la lógica mercantil.

Curiosamente, pese a la extraordinaria influencia de estos discursos en la acción empresarial y posteriormente política, su análisis no ha sido central en prácticamente ninguna disciplina de conocimiento hasta tiempos relativamente recientes. Sin embargo, a lo largo del siglo xxi se ha hecho más evidente la influencia del gerencialismo (por sus efectos en la construcción de sociedades cada vez más desiguales, véase Alonso, 2007), lo que ha generado no solamente un corpus de publicaciones decisivo para la comprensión del fenómeno (recordemos a los ya citados Boltanski y Chiapello, 2002; Du Gay, 2012, o Laval y Dardot, 2013), sino la popularidad de escuelas críticas con ese gerencialismo como son los denominados Critical Management Studies, que desde el terreno de la disciplina de la administración de empresas han planteado algunas de las críticas más suge- 
rentes. Sin embargo y pese a este renacimiento general de la crítica, en el espacio hispanohablante, aunque dicha crítica está empezando a surgir con fuerza, sigue siendo relativamente poco conocida.

El presente número de Recerca tiene como objetivo dar a conocer, a través de la fórmula del monográfico (ideal para reunir estas investigaciones todavía un tanto fragmentadas), estos trabajos críticos, para lo que va a recopilar un conjunto de reflexiones que examinan, desde muy diferentes ámbitos -sociología, filosofía, relaciones industriales o teoría organizacional- estos discursos del management. Procedemos a continuación a describir los temas tratados en las diferentes contribuciones que forman esta, a nuestro juicio, muy interesante colección de textos.

En primer lugar, Ernesto Gantman (Universidad de Buenos Aires y Universidad de Belgrano, Argentina) reflexiona «En torno al potencial transformador de los CMs (Critical Management Studies)». En su ensayo, el autor examina dicha corriente en términos de su potencial transformador respecto al mundo del trabajo. Es decir, Gantman nos inscribe en el marco teórico que da sentido a este monográfico, esto es, la caracterización de los CMS (Alvesson y Willmott, 1992) y de su desarrollo histórico hasta nuestros días (Gantman, 2009). A partir de la aproximación crítica que dicha corriente realiza frente a los estudios del management, el autor argumenta que los смs no se agotan en su versión británica, sino que se desarrolla y amplía al trabajo de académicos/as de otros países con afiliaciones institucionales en ciencias sociales distintas a la administración (Gantman, 2016; Gantman y Fernández Rodríguez, 2008). Finalmente, se concluye que la pluralidad disciplinaria de los cms y el tipo de preocupación intelectual que los motiva permiten identificar un rol transformador más afín a disciplinas como la sociología que al campo de la administración dentro de dicha corriente. De este modo, más que agentes de cambio organizacional, los/as académicos/as que trabajan dentro del ámbito de los CMs, podrían convertirse en intelectuales públicos comprometidos con la denuncia de las ideologías gerenciales y económicas dominantes.

En segundo lugar, se sitúa el trabajo de la autora Marisa Vázquez Mazzini (Instituto de Desarrollo Económico y Social, Centro de Antropología Social, Argentina) titulado «Entre la racionalidad instrumental y el imaginario managerial. Estrategias didácticas en la enseñanza del Management». Su aportación a este monográfico se centra en un estudio sobre la enseñanza del management a cargos directivos de diferentes corporaciones. Así, del enfoque mayormente académico que Gantman había aportado más arriba, pasamos a otra cuestión clave a la hora de definir cómo se desarrolla la tarea del/la mánager: identificar los puntos centrales del discurso subya- 
cente a las enseñanzas del management en su sentido más directo (Vázquez Mazzini, 2015). Es decir, el de las escuelas de negocios y cursos de especialización para gerentes. La autora realiza esta tarea a partir del registro etnográfico correspondiente a un curso de liderazgo en una escuela de negocios de Buenos Aires (Argentina), donde aborda la relación entre los objetivos educacionales (el "para qué» de la enseñanza), el contenido (el «qué» de la enseñanza) y las interacciones dentro del aula. Su trabajo acaba por mostrar que la tensión entre la lógica de la eficiencia y la lógica vincular del «imaginario managerial» (Alonso y Fernández Rodríguez, 2006) condiciona la actividad de docentes y cursantes.

En tercer lugar, David Muñoz-Rodríguez y Antonio Santos Ortega (Universitat de València) abordan la precariedad derivada de los discursos economicistas vigentes en la formación universitaria a través de su artículo «Las cárceles del capital humano: trabajo y vidas precarias en la juventud universitaria». Centrándose en el discurso de la lógica del capital humano y la activación dirigido al estudiantado universitario, los autores reflexionan en torno a los procesos de flexibilización y precarización que son puestos en marcha ya en el ámbito universitario y que van a condicionar las trayectorias, tanto vitales como laborales, de la juventud (Santos Ortega, 2013). Así pues, los autores señalan que la universidad se ha convertido en gran medida en el campo donde recae con más fuerza el mito del capital humano y la prescripción de convertirse en un "empresario de sí mismo», con lo que la formación se concibe como un proceso de automejora constante sin fin. Esta inversión individual, guiada por la tasa de rendimiento futuro, provoca que los/as jóvenes que estudian se conviertan en inversores/as: invierten en su capital para incrementar la posibilidad de obtener rentas futuras, inmersos/as en un contexto de crisis (Gentile, 2015). Sin embargo, nadie les advierte de las nuevas precariedades que esta práctica acaba por suscitar (Muñoz-Rodríguez y Santos Ortega, 2015; Santos Ortega y MuñozRodríguez, 2015), y que les convierte en empresarios/as cuya única posesión es un capital humano que nadie desea contratar.

En cuarto lugar, pasamos a la materialización del presupuesto del/la «empresario/a de sí mismo/a», con la aportación de Álvaro Briales (Universidad Complutense de Madrid y Fundación de los Comunes) titulada «Emprendeudores fracasados: individualización neoliberal en los discursos sobre el desempleo». En este artículo Briales analiza el discurso del emprendimiento que, según su opinión, opera como un dispositivo de individualización de la relación salarial que oculta el fuerte contraste entre el plano ideal -autonomía, independencia subjetiva, éxito- y los obstáculos materiales reales - profundización del endeudamiento, alta proporción de fraca- 
so, precarización- (Briales, 2016). A través de su trabajo se puede concluir que las políticas de empleo que promocionan el emprendimiento como fórmula para aplacar el enorme desempleo actual, no resuelven dicho problema sino que sirven fundamentalmente para gobernar políticamente la precariedad masiva (Briales y López Calle, 2015). En base a sus conclusiones, Briales propone utilizar las categorías «emprendeudores» $\mathrm{y}$ "emprendeudamiento» para una mejor comprensión sociológica del discurso del emprendimiento y sus nocivas implicaciones para la ciudadanía.

En quinto lugar, Borja García Ferrer (Universidad de Granada) aborda los riesgos del discurso individualista en el mundo virtual mediante el artículo «El precio del progreso: de la virtualización del mundo al zombismo hiperindividualista». El autor identifica las nuevas tecnologías de la comunicación como las herramientas a través de las cuales el capitalismo basa su fuerza y expansión. Desde su perspectiva, es a través de las nuevas posibilidades digitales como se transforma la estructura normativa de la sociedad predigital, de lo que se sigue una hiperinversión del individuo en lo privado y una desmovilización del espacio público. Según García Ferrer (2015), este espacio público se convierte en un inquietante desierto donde zombis hiperindividualistas interactúan en el simple sentido de la palabra, al ritmo de las informaciones decididas por los nuevos expertos en las artes de la infoesfera. A través de esta realidad se realza una visión aséptica de la libertad, entendida como simple libertad de elección ante la oferta ilimitada del mercado. De esta manera, la opción de vida «hiperindividualista» (Oliveira, 2010), se convierte en la predominante, alejando cada vez más a las personas unas de otras y descolectivizando el espacio público.

En sexto lugar, encontramos el trabajo de Guacimara Gil (Universidad de Las Palmas de Gran Canaria), quien en su artículo "Análisis discursivo del relato empresarial sobre Responsabilidad Social Corporativa. Coordenadas narrativas y prácticas discursivas», reflexiona en torno al discurso de la clase directiva española acerca de la Rsc. La autora presenta los resultados del análisis discursivo realizado sobre las producciones verbales elaboradas por Directivos de Responsabilidad Social (DIRSE) para explicar qué son y cómo se organizan sus políticas socialmente responsables. En base a sus hallazgos, concluye que la élite empresarial española repele aquellas significaciones vinculadas al campo semántico de la caridad e incorpora el protagonismo de la innovación como símbolo de la RSC (Gil, 2016a; 2016b). Con este ejercicio de «expulsión» discursiva, se hace hincapié en los límites estructurales que el sistema económico impone y la defensa de la presunción de complejidad de las empresas. 
Por último, y para cerrar este monográfico sobre discursos del management, las autoras Margarita Pérez Osorno y Angie Betancur Vargas (Universidad de Antioquia, Colombia), nos introducen en la materialización de la gestión a través de un estudio de caso referido a la «Gestión del sector minero en el ámbito colombiano y su relación entre el accionar gubernamental y empresarial». Las autoras parten de la innovación en los medios de producción que ha llevado a cabo el Gobierno colombiano en los últimos años, centrándose en el campo de la minería. Estas acciones, lanzadas con el fin de generar estrategias competitivas que permitan la incursión de dicho país en la esfera del mercado mundial, provocan que se creen nuevas sinergias entre el accionar gubernamental y empresarial. Sin embargo, tal y como las autoras dan por afirmar, el territorio colombiano se encuentra bastante desprotegido por el Estado, lo que ha generado fuertes repercusiones en el desarrollo de esta actividad en las áreas donde esta radica, y que reclama por tanto, una mejora en la gestión de dicho sector por todas las partes implicadas en la misma.

Como se puede observar, el presente monográfico de Recerca reflexiona en torno a los nuevos discursos del management, a través de la identificación de diferentes cuestiones como son la precarización, el emprendimiento, el desempleo, el individualismo, la innovación, la Responsabilidad Social Corporativa y la gestión gubernamental. A través de estos pilares de la sociedad actual, podemos observar cómo la lógica mercantil neoliberal forma parte de la vida diaria de las personas y de las organizaciones. En consecuencia, estamos hablando de una lógica vital que trasciende los límites de la esfera económica, para acabar convirtiéndonos en gestores/ as de nuestro propio destino en un marco de incertidumbre y precariedad; una realidad que pone de relieve la crucial importancia de desarrollar reflexiones críticas en torno a los discursos del management (Fernández Rodríguez, 2007a; 2007b).

\section{BIBLIOGRAFÍA}

Alonso, L. E. (2007): La crisis de la ciudadanía laboral, Barcelona, Anthropos.

Alonso, L. E. y Fernández Rodríguez, C. J. (2006): «El imaginario managerial: el discurso de la fluidez en la sociedad económica», Política y Sociedad, 23(2), pp. 127-151. 
- (2013): «Los discursos del management: una perspectiva crítica», Lan Harremanak, 28, pp. 42-69.

Alvesson, M. y Willmott, H. (eds.) (1992): Critical Management Studies, Londres, Sage.

Boltanski, L. y Chiapello, E. (2002): El nuevo espíritu del capitalismo, Madrid, Akal.

BRIALEs, Á. (2016): El tiempo superfluo: una sociología crítica del desempleo. El caso de España (2007-2013), tesis doctoral inédita, Universidad Complutense de Madrid. Disponible en: https://ucm.academia.edu/ AlvaroBriales [Consultado el 19 de diciembre de 2016].

Briales, Á. y López Calle, P. (2015): «El paro productivo. La crisis como producción de desempleo para la reactivación de la rentabilidad empresarial», Revista de Economía Crítica, 20, pp. 86-101.

Du GAY, P. (2012): En elogio de la burocracia, Madrid, Siglo XxI.

Fernández Rodríguez, C. J. (2007a): «Postmodernidad y teoría crítica de la empresa. Una presentación de los Critical Management Studies», en Fernández Rodríguez, C. J. (ed.) (2007): Vigilar y organizar. Una introducción a los Critical Management Studies, Madrid, Siglo XxI.

- (2007b): El discurso del Management: tiempo y narración, Madrid, cIs.

Gantman, E. (2005): Capitalism, Social Privilege and Managerial Ideologies, Aldershot, Ashgate.

- (2009): «Reflexiones sobre la evolución de las ideologías gerenciales desde el siglo xix hasta el presente», Energeia, 5(1), pp. 96-115.

- (2016): "CMs in the periphery: A look at South America», en Grey, C., Huault, I., Perret, V. y Taskin, L. (eds.) (2016): Critical Management Studies. Global Voices, Local Accents, Londres, Routledge.

Gantman, E. y Fernández Rodríguez, C. J. (2008): «Notas sobre la evaluación del conocimiento administrativo en la República Argentina y su comparación con el caso español (1913-2007)», Cadernos EBAPE.BR, 6(4), pp. 115-135.

García Ferrer, B. (2015): «De las máquinas totalitarias al Capitalismo emocional. Consideraciones en torno a la impostura de la deshinibición", Agora:papeles de Filosofía, 34(1), pp. 189-211.

Gentile,A. (2015): «Jóvenes titulados superiores en la encrucijada de la crisis", Recerca. Revista de Pensament i Anàlisi, 16, pp. 35-58.

GIL, G. (2016a): Revisión crítica de la noción empresarial «Responsabilidad Social Corporativa». Una aproximación genealógico-discursiva, Las Palmas de Gran Canaria, ULPGC. Disponible en: http://acceda.ulpgc. es/handle/10553/18930 [Consultado el 12 de diciembre de 2016]. 
- (2016b): «Análisis genealógico de la noción Responsabilidad Social Corporativa construida por el mundo de los negocios. Parte I: Producción Académica y Escuelas de Negocios», en el xII Congreso Español de Sociología. Comunicación oral en el Grupo de Trabajo, 31 (Sociología Económica), 1 de julio de 2016, Gijón, España.

LAVAL, C. y DARDOT, P. (2013): La nueva razón del mundo. Ensayo sobre la sociedad neoliberal, Barcelona, Gedisa.

Muñoz-Rodríguez, D. y Santos Ortega, A. (2015): «Las nuevas precariedades a través de las au pairs universitarias. Del cosmopolitismo al trabajo de cuidados de bajo coste", Prisma Social, 15, pp. 526-561.

Oliverra, C. (2010): «Acerca de las aporías del hiperindividualismo contemporáneo", en Aranzueque, G. (ed.) (2010): Ontología de la distancia, Madrid, Abada.

Powell, F. (2015): «The Psych-politics of Austerity; Democracy, Sovereignty and Civic Protest», Recerca. Revista de Pensament i Anàlisi, 15, pp. 15-31.

Santos Ortega, A. (2013): «Fuga de cerebros y crisis en España: los jóvenes en el punto de mira de los discursos empresariales», Áreas. Revista Internacional de Ciencias Sociales, 32, pp. 125-137.

Santos Ortega, A. y Muñoz-Rodríguez, D. (2015): «Fuga de cerebros y biografías low cost: nueva etapa en la precarización de la juventud", Recerca. Revista de Pensament i Anàlisi, 16, pp. 13-33.

Tormey, S. (2015): «Democracy Will Never Be the Same Again: $21^{\text {st }}$ Century Protest and the Transformation of Politics», Recerca. Revista de Pensament $i$ Anàlisi, 15, pp. 107-128.

VÁzquez Mazzini, M. (2015): «Palabras lindas, crudas realidades. Reflexiones sobre la enseñanza y el aprendizaje de la ideología empresarial», Prácticas de oficio. Investigación y reflexión en Ciencias Sociales, n. ${ }^{\circ}$ 14. Disponible en http://ides.org.ar/wp-content/uploads/2015/02/Vazquez-texto.PDF. 